\title{
A Validation Study of the Greek Version of the Toronto Empathy Questionnaire in Medical Students and a Measurement of Their Empathy
}

Polychronis Voultsos ( $\sim$ pvoultsos@auth.gr)

Aristotle University

Angeliki Papana

University of Macedonia

Fotios Chatzinikolaou

Aristotle University

Aspasia Deliliga

AHEPA University Hospital

\section{Research Article}

Keywords: Empathy, therapeutic relationship, Toronto 52-item, Hotelling's T-Squared Test

Posted Date: June 3rd, 2021

DOI: https://doi.org/10.21203/rs.3.rs-566867/v1

License: (1) (1) This work is licensed under a Creative Commons Attribution 4.0 International License.

Read Full License 


\section{Abstract}

\section{Aims and objectives}

Empathy is an important key driver of any therapeutic relationship. It is beneficial not only to the patients, but also to physicians. Enhancing physician's empathy should be an important goal of medical education. As there is a literature gap regarding the topic of empathy among medical students in Greece, this study aims to contribute to filling this gap.

\section{Methods}

A cross-sectional study was conducted. The (validated in Greece) Greek version of Toronto 52 -item empathy 6-point Likert-scale was administered to all the medical students in the Aristotle University of Thessaloniki, in Greece. In addition, participants were asked to provide information regarding their sociodemographics. A demographic comparison was conducted.

\section{Results}

The preliminary validation of the Greek version of the Toronto Composite Empathy Scale (TCES) demonstrated acceptable validity and reliability among medical students and could be further tested in larger samples of medical students. The overall reliability analysis of the TCES questionnaire is high (Cronbach's $a=0.895$, Sig. from Hotelling's T-Squared Test $<0.000$ ). The mean total score of empathy showed that students have a moderately high empathy. The 52-item TCES, 26 for the personal (Per) setting and another 26 for professional (Pro) life, equally divided into cognitive (Cog) and emotional (Emo) empathy in each case. It was found that there is a statistically significant difference in means between the Per-Cog and Per-Emo settings (Sig < 0.001), the Pro-Cog and Pro-Emo (Sig < 0.001), the PerCog and Pro-Cog (Sig = 0.004), and the Per-Emo and Pro-Emo (Sig < 0.001). Females had significantly higher empathy scores (mean score 208.04) than males (mean score 192.5) on the Per-Cognitive, Per-Emo and Pro-Emo subscales. Furthermore, a positive correlation was found between empathy and factors such as love for animals, interest in medical ethics, belief in God, having an ill person in the family, class year or carrier intention.

\section{Conclusions}

The Toronto Composite Empathy Scale (TCES) is applicable to medical students. For the most part our findings were consistent with previous literature. However, we identified some nuances that might draw researchers' attention.

\section{Background}

\section{What is empathy in the context of health care}


Empathy is difficult to define and constitutes a controversial concept with different components. It is a multilayered phenomenon [1]. In the context of health care and medical education, it is defined as the capacity of understanding of the patient's situation, inner experiences, feelings, concerns and perspectives (view the outside world from the other person's perspective), combined with a capacity to communicate that understanding and act helpfully on that understanding [2-6]. However, an empathetic physician should not engage with patients' feelings, emotions and perspectives [7]. Larson and Yao put it best in saying "clinical empathy has been compared to an actor's skill at engaging in and reacting to others' emotions" [8]. Joining the feeling of the patient is sympathy [9]. Empathy and sympathy have different neurophysiological background [10]. Evidence from neuroscience that conceptualises empathy as predominantly an intellectual response involving the neocortex of the brain, and sympathy as predominantly an emotional response involving the limbic system of the brain [11]. Emotional regulation is a key component to an appropriate empathic response [12]. Lack of emotional regulation limits physician's cognitive resources which should be available to cure his or her patient [13]. Better emotional regulation leads to more functional affective empathy [4].

Recently, it has been argued that there is a positive association between self-esteem and empathy [14], and that enhancing students' ability to introspect (self-awareness) is crucial to enhance their empathy [4].

In the context of health care (at least), empathy is considered a complex and multidimensional concept that has cognitive, emotional, moral, and behavioural dimensions [15-17].

In psychology, new empathy models have been developed to capture the essence of empathy, such as the mirror-neuron theories [18] and perception-action model (PAM) [19]. Preston and de Waal argue that empathy is a deeply personalized phenomenon, and any model that fails to address this does not capture its essence. The authors argue that perception-action model (PAM) is a significantly broader concept that encompasses the mirror mechanism but also "takes into account the deeply personal way that empathy depends on personal experience", thus providing a deeper explanation of empathy [20].

\section{The distinction between cognitive and affective component of empathy}

Some authors consider that cognitive empathy is distinguished from affective empathy [21]. Furthermore, it is argued that the cognitive component is the most prevalent, whereas the affective is the least $[22,23]$. Several studies used a definition for empathy proposed by Hojat and LaNoue [24], which regards empathy as a predominantly cognitive attribute [25]. Gladstein who conceptualizes empathy as a two-dimensional model (cognitive and affective dimension), has long before simply and clearly described these dimensions. The author states that the cognitive component refers to 'intellectually taking the role or perspective of another person', whereas the affective component consists of 'responding with the same emotion to another person's emotion' [26]. Preston and de Waal consider a clear distinction between emotional and metacognitive empathy [27]. Emotional empathy may be an automatic process [28] while meta-cognitive empathy is an effortful perspective-taking which is considered significant in the clinical context [29]. Effortful perspective-taking decreases personal distress and increases empathetic concern 
[30]. Hojat and colleagues portrayed 'perspective-taking' as a core ingredient of empathy (especially in the patient-physician relationship), which however, can hardly be distinguished from 'standing in the patients' shoes' (a second ingredient). The third ingredient is 'compassionate care' [2, 24]. It is noteworthy that Hojat et al. suggest that "physician empathy is a multidimensional concept involving at least three components. The most important component is perspective taking, an outcome consistent with that reported for the general population. Other components of empathy are compassionate care and standing in the patient's shoes, which are both specific to the patient-physician relationship" [2]. Hojat et al. define empathy as "a cognitive (as opposed to affective) attribute that involves an understanding of the inner experiences and perspectives of the patient, combined with a capability to communicate this understanding to the patient" [9]. Furthermore, the authors state, "The key feature of empathy, according to our definition, is understanding, rather than affective involvement with patients' experiences. The affective domain is a key component of sympathy, rather than empathy" [9]. Other authors state that "clinical empathy-the compassionate professionalism of a skilled clinician-is affective and metacognitive, contextual and interpersonal, and difficult to assess" [27, 29]. "While it relies on general empathy-the compassion and understanding in everyday life-it also requires a degree of emotional detachment and objectivity" [29]. Perspective-taking "is similar to, but clearly not the same as, cognitive empathy" [31]. A great part of literature emphasizes cognitive empathy as most important to the relationship between physician and patient. However, it is arguably stated that "this conceptualization is both simplistic and misleading" [32]. It is true that the distinction between cognitive and affective component of empathy is relevant. For instance, it is argued that "the cognitive dimension seems more receptive to a training program, while the affective component would be more innate" [33]. However, "these components are intimately linked and interdependent" [34,35]. The cognitive and affective component of empathy are interwoven. de Waal and Preston state: "Recent research on empathy in humans and other mammals seeks to dissociate emotional and cognitive empathy. These forms, however, remain interconnected in evolution, across species and at the level of neural mechanisms" [19].

There is convincing empirical evidence from developmental science, social neuroscience, and clinical neuroscience that the cognitive and affective facets of empathy interact in the experience of empathy" [32]. Ponnamperuma, Yeo and Samarasekera put it best in saying "notwithstanding the cognitiveaffective dichotomy, most studies view empathy as a holistic construct, while acknowledging its different dimensions" [36].

\section{The role of empathy in clinical practice}

There is evidence suggesting that a physician's empathy not only plays a central role in the physicianpatient relationship (promotes the patient-centered communication which stands at the very heart of medicine), but also positively affects the patient's satisfaction as well as the therapeutic outcomes [2, 36-45]. Empathy is strongly related to the humanitarian aspect of medicine. Patient-oriented care is at the core of holistic care. Students that participated in qualitative research considered that empathy is a virtue that makes you a 'better', more selfless person [46]. 
Hojat concludes "that empathic engagement in the health care and human services is beneficial not only to the patients, but also to physicians, other health care providers, administrators, managers, health care institutions, and the public at large" [47].

Hojat et al. and Steinhausen et al. emphasize the relationship between physician's empathy and trauma surgery patients and diabetic patients, respectively $[39,48]$.

There is evidence that empathetic physicians have higher levels of clinical competence [49] and reduced number of legal claims against them [6]. In that connection, the Association of American Medical Colleges (1998) stated that "physicians must be compassionate and empathetic in caring for patients and must be trustworthy and truthful in all of their professional dealings". "Anyhow, all authors agree to say that empathy is important" [4]. At any rate, empathy motivates prosocial behavior. Note, however, that this motivation is context - dependent [50].

\section{"Teaching" medical students to be empathetic}

Enhancing physician's empathy should be an important goal of medical education $[6,17,23,51]$. There is "a need to incorporate a regular training program into the existing medical curriculum, to enhance empathy and prevent its decline over the years" [52]. Multi-institutional international research would be most helpful for this to be done [53].

Literature has raised the question whether empathy is a teachable (acquired) skill or a hereditary trait. Indeed, both cognitive and affective empathy are said to be associated with hormones (dopamine / testosterone and oxytocin / arginine-vasopressin / serotonin, respectively) [10]. Moreover, it is argued that specific gene's function may be associated to empathy. It is suggested a significant association between the rs53576 OXTR gene polymorphism and empathy (particularly the affective aspect of empathy), especially among women [54]. Note, however, that environmental influences may play a key role to the expression of these particular genes. Kataoka et al. concluded that "targeted educational programs to enhance empathy in medical students can have a significant effect" [55]. Many studies suggest that undergraduate studies should include a range of intervention strategies to enhance students' empathy of medical students [56] or dental students [57]. As presented below (Discussion section), research has shown a striking decline in empathy over the years as medical studies progress. Dehning et al. found very low empathy among first-year medical students and highlights the need for "inclusion of specific training in cognitive and emotional empathy in medical education" [58]. Ye et al. highlight that "empathy-focused training during early clinical contact can improve the empathetic capacity of undergraduate medical students" [59].

Hojat provided "10 approaches for enhancing empathy in medical education: improving interpersonal skills, audio- or video-taping of encounters with patients, exposure to role models, role playing (aging game), shadowing a patient (patient navigator), hospitalization experiences, studying literature and the arts, improving narrative skills, theatrical performances, and the Balint method" [47]. Note, however, that 
some authors suggested that the empathetic skills enhanced through these interventions' strategies (which may significantly increase immediately after an intervention) may degrade over time [60, 61].

Already, in many countries medical schools have attempted to develop strategies to enhance empathy in their medical students [25]. Even if there is intrinsic motivation and self-efficacy, a supportive learning environment in required to develop students' effective clinical empathy in various clinical contexts [25]. The General Medical Council $[62,63]$ as well as the Association of American Medical Colleges $[64,65]$ have emphasized the need for teaching empathy as a professional skill and competency. Importantly, humanities curriculum ("an extensive 3-year preclinical medical humanities curriculum") may prevent the empathy decline [6]. Olsen and Gebremariam found that medical students "who majored in humanities or interpretive social sciences disciplines have higher empathy scores than their peers who majored in the positivistic social sciences and STEM (science, technology, engineering, and mathematics) disciplines" [66].

Note, however, that theoretical education is necessary though not sufficient to enhance students' empathy. Santiago et al. found medical student's "empathy levels being higher when earlier and more intense contact with patients accompanied by skilled tutors was developed" [67]. It arguable that "hands-on approaches to diagnosis and treatment, and patient-centered care" may play a crucial role in enhancing medical students' empathy [68]. Rivas put it best in saying: "First, academic workshops and group forums, supervised by doctors with bioethics training, can introduce empathy and related topics for discussion. Second, clinical rotations can help students to gain additional insights through interactions with patients and learning about their real-life experiences as patients in the health care system" [69]. It is arguably highlighted the role of the contact between medical students and patients in enhancing their empathy. Interestingly, Davison and Lindqvist strongly suggest the benefits of medical students working as health care assistants [70].

It is crucial to bear in mind that "while students may understand the importance of empathy, there is currently no consensus on the appropriate method for teaching this quality" [71]. For instance, a widely used method of enhancing medical students' empathy is the role-play and "the participation in both sides of the doctor-patient partnership" [72]. At any rate, it is crucial to bear in mind that "the current empathy intervention literature is limited by a variety of methodological weaknesses" [60].

At any rate, the crucial question is whether empathy "is a 'nature' or 'nurture' phenomenon or a combination of both". It remains unclear [49]. It has been argued that empathy is an innate attribute and early upbringing-driven capacity, which can be enhanced by learning [73].

Empathy in medical education is not a "virgin" topic in research. However, there are still many gaps to be filled. In Greece, limited research has been conducted on this topic. This study aims to contribute to filling this gap.

\section{Research questions}


The primary research question that defined the focus of this study was as follows:

Is the Greek version of the Toronto Composite Empathy Scale (TCES) applicable to medical students?

The secondary research questions were as follows:

What are the empathy levels among medical students at the Aristotle University of Thessaloniki (Greece)?

How are some lifestyle or socio-demographic factors correlated with empathy among medical students at the Aristotle University of Thessaloniki (Greece)?

\section{Ethical considerations}

All participants were provided with information, regarding the purpose of the study. The responses were anonymized and explicit consent to participate was provided by all participants to proceed with filling in the questionnaire. Participants were assured that their personal data would be kept confidential. The ethical principles of anonymity, voluntary participation and confidentiality were considered. The participants' anonymity and confidentiality were maintained throughout the study. The study and consent procedure were approved by the ethics committee affiliated with Aristotle University of Thessaloniki, Faculty of Health Sciences, Department of Medicine (No: 5/23.2.2021).

\section{Materials And Methods}

The study was conducted through social media between February and May 2021. More specifically, a questionnaire was distributed via Google Forms to students at the School of Medicine of the Aristotle University of Thessaloniki. The survey was answered anonymously and contained 20 demographics questions, such as age, gender, financial status of family, siblings, the specialty students intend to follow. The second part of the questionnaire consisted of 52 items from the Greek version of the Toronto Composite Empathy Scale (TCES), 26 for the personal (Per) setting and another 26 for professional (Pro) life, equally divided into cognitive ( $\mathrm{Cog}$ ) and emotional (Emo) empathy in each case. Therefore, we examined the four thirteen-item subscales (Per-Emo, Per-Cog, Pro-Emo, Pro-Cog) and the overall empathy scale. A six-point Likert scale with no neutral position was used in the analysis. Items are scored as follows: at no time $=1$, most of the time $=2$, slightly less than half times $=3$, slightly more than half times $=4$, some of the time $=5$, all the time $=6$. The Greek version of the TCES has previously been validated among dental students [74]. We wondered whether it might also be applicable to medical students. As the Greek version of the TCES demonstrated acceptable validity and reliability among dental students, we hypothesized that in all likelihood it also might be validated in the environment of medical students provided that the items of the questionnaire were not specific for dental students.

Note that $96.4 \%$ of the participants declared that became aware of the nature and purpose of the research or/and on the collection, processing, and storage of the data, while the remaining $3.6 \%$ are missing values. 


\section{Statistical analysis}

Descriptive statistics were used to summarize the demographic characteristics of the participants, such as frequency distributions and percentages. Regarding the TCES items, the subscales and total scores, means and standard deviations are displayed. The associations between the demographics are reported in terms of the chi-2 independence tests. The internal consistency of the subscales and of the TCES questionnaire was analyzed with Cronbach's a and Hotelling's T-Squared Test. Pearson's Correlation Coefficient is estimated to investigate possible relationships between the individual items. The mean differences between the subscales are investigated based on Paired Samples t-tests. Significant differences between the subscales and TCES from subgroups on the demographic characteristics are established using Independent Sample T-Tests and One-way ANOVAs.

The analysis was performed using the statistical program SPSS 25.0 (Statistical Package for the Social Sciences) of IBM.

\section{Results}

\section{Demographics}

A total of 224 medical students participated in this study, whereas $65.2 \%$ were women and $33.9 \%$ men. Most of the participants were up to 25 years old (91.1\%), 7.6\% were up to 35 years old and the remaining $1.3 \%$ were over 35 years old. Almost half of them were born in a big city (48.7\%), $37.1 \%$ in a provincial town, $7.6 \%$ in a town and $4.9 \%$ in a village. $37.5 \%$ of the participants grew up in a big city, $35.7 \%$ in a provincial town, $14.7 \%$ in a town, and $12.1 \%$ in a village $89.7 \%$ of them were born and $90.6 \%$ were raised in Greece. $71.9 \%$ of the participants live now together with other people. $74.6 \%$ never had or is going through a serious adventure with his/her health.

Regarding the family they were raised, $58.9 \%$ replied that were raised in a large family. A high percentage of the participants has siblings (92\%) and does not have children (97.8\%). Most of them were raised in a house without grandparents or elderly people (77.2\%). In their family or in their immediate environment there was or is a person who is seriously ill with a percentage of $46 \%$. Their families mainly did not have enough financial comfort nor financial difficulties (44.6\%), some had enough financial comfort $(29.9 \%)$ and even fewer went through difficult phases financially (21.9\%). At least one parent of the participants graduated from the university $(78.6 \%)$.

According to their love to animals, over half of them love animals very much (53.6\%), quite love them (33.5\%), very little love animals (8\%), do not care about animals (4\%) and $0.9 \%$ hate them.

The highest participation is from students in their 1 rst year of studies, followed by 3rd years students (18.3\%), 2nd years students (16.5\%), 6th year (13.4\%), 4th year (12.5\%), 5th year (10.7\%) and finally on their degree (2.2\%). Regarding the specialty they want to follow, the highest percentages are for General Surgery $(9.8 \%)$, do not know $(9.4 \%)$, psychiatry $(7.6 \%)$, pediatrics $(7.1 \%)$. Almost half of them have not 
decided on their future career (42.9\%), $25.4 \%$ intend to work on public sector, $20.1 \%$ in private sector and $11.6 \%$ intend to follow an academic career. Finally, $46.9 \%$ are moderately interested in being informed often about medical ethics issues, $37.1 \%$ are very interested, $14.3 \%$ are a little interested and $1.3 \%$ are not interested at all.

Religious are the $62.1 \%$ of them, $21 \%$ do not believe in God and the remaining do not know or wanted to answer this question.

\section{TCES items}

The TCES questionnaire has been replied by 224 students. Missing values for Personal setting vary from 0 to 3, while an increased number is obtained for Professional setting reaching out 40 missing replies. A significant negative correlation was found between the number of missing replies of each participant and the study year (Pearson $=-0.336$, Sig. $<0.000$ ), with students from 1 rst and 2 nd years mainly not responding to most items.

Table 1 displays the descriptive statistics for TCES items with professional setting. The highest values, indicating more empathy, were revealed for items Q9 ${ }^{\mathrm{R}}, \mathrm{Q} 35^{\mathrm{R}}, \mathrm{Q} 26^{\mathrm{R}}$, while the minimum values (less empathy) were revealed for items Q50, Q36, Q10. Mainly positive correlations are observed between the TCES items, with strongest ones for Q7 ${ }^{\mathrm{R}}-\mathrm{Q} 33^{\mathrm{R}}(0.724), \mathrm{Q} 10$ - Q36 (0.651), Q14 - Q40 (0.633) and Q38 - Q47 (0.613). 
Table 1

Descriptive statistics for subgroup scales with personal setting. Items with reversed scores are noted with superscript ${ }^{R}$.

\begin{tabular}{|c|c|c|c|c|c|}
\hline \multicolumn{4}{|c|}{ Cognitive } & \multicolumn{2}{|c|}{ Emotional } \\
\hline Item & Mean & SD. & Item & Mean & SD. \\
\hline Q1 & 4.12 & 1.262 & Q5 & 3.71 & 1.489 \\
\hline Q2 & 4.58 & 1.289 & $\mathrm{Q} 7^{\mathrm{R}}$ & 2.84 & 1.178 \\
\hline Q3 ${ }^{\mathrm{R}}$ & 4.75 & 1.030 & Q10 & 2.13 & 1.131 \\
\hline Q4 & 4.33 & 1.273 & Q12 & 3.48 & 1.539 \\
\hline Q6 & 4.77 & 0.938 & Q13 & 2.75 & 1.325 \\
\hline Q8 ${ }^{R}$ & 4.03 & 1.287 & Q15 ${ }^{R}$ & 3.28 & 1.448 \\
\hline Q9 R & 5.25 & 0.935 & Q16 & 3.44 & 1.262 \\
\hline Q11 & 3.23 & 3.48 & Q18 & 4.61 & 1.193 \\
\hline Q14 & 4.12 & 1.268 & Q20 & 3.83 & 1.443 \\
\hline Q17 & 4.81 & 0.910 & Q21 & 3.17 & 1.450 \\
\hline Q19 & 4.11 & 1.335 & Q24 & 3.23 & 1.286 \\
\hline Q22 & 4.81 & 0.949 & $\mathrm{Q} 25^{\mathrm{R}}$ & 4.29 & 1.318 \\
\hline Q23 R & 4.28 & 1.176 & Q26 ${ }^{\mathrm{R}}$ & 4.95 & 1.121 \\
\hline
\end{tabular}

Table 2 displays the descriptive statistics for TCES items with professional setting. 
Table 2

Descriptive statistics for TCES items with professional setting. Items with reversed scores are noted with

\begin{tabular}{|c|c|c|c|c|c|}
\hline & Cogniti & & & Emotic & \\
\hline & Mean & SD. & & Mean & SD. \\
\hline Q27 & 4.15 & 1.243 & Q31 & 2.56 & 1.217 \\
\hline Q28 & 4.75 & 1.084 & Q33 R & 2.71 & 1.134 \\
\hline Q29 R & 4.93 & 0.979 & Q36 & 2.12 & 1.170 \\
\hline Q30 & 4.39 & 0.979 & Q38 & 3.49 & 1.607 \\
\hline Q32 & 4.64 & 0.993 & Q39 & 2.65 & 1.286 \\
\hline Q34 R & 4.31 & 1.231 & Q41 ${ }^{\mathrm{R}}$ & 2.53 & 1.161 \\
\hline Q35 ${ }^{R}$ & 5.24 & 0.997 & Q42 & 2.61 & 1.190 \\
\hline Q37 & 3.70 & 1.336 & Q44 & 4.87 & 1.168 \\
\hline Q40 & 4.35 & 1.271 & Q46 & 3.51 & 1.457 \\
\hline Q43 & 4.60 & 1.044 & Q47 & 3.28 & 1.579 \\
\hline Q45 & 3.64 & 1.435 & Q50 & 2.02 & 1.075 \\
\hline Q48 & 4.87 & 1.007 & $\mathrm{Q} 51^{\mathrm{R}}$ & 4.28 & 1.307 \\
\hline Q49 R & 4.56 & 1.042 & $\mathrm{Q} 52^{\mathrm{R}}$ & 4.81 & 1.258 \\
\hline
\end{tabular}

\section{TCES subscales}

As previously discussed, missing answers were mainly from the Professional setting. Therefore, 215 and 216 valid cases were considered for the Per-Cog and Per-Emo settings, respectively, while for the Pro-Cog and Pro-Emo only 43 valid cases were found.

First, the internal consistency of each subscale has been established on Cronbach's a, which indicated that the set of items of each subscale are closely related as a group. Specifically, $a=0.748$ for Per-Cog, $a$ $=0.806$ for Per-Emo, $a=0.830$ for Pro-Cog, $a=0.805$ for Pro-Emo. Hotelling's T-Squared Test further confirmed that all items on the scale have the same mean (Sig. $<0.001$ for all subgroups).

Possible scores for each of the four subscales (Per-Cog, Per-Emo, Pro-Cog, Pro-Emo) range from 13 to 78, where higher scores refer to greater levels of empathy. The mean score (and standard deviation, SD) on the Per-Cog was 57.14 (SD = 7.49), on the Per-Emo was 45.73 (SD = 8.00), on the Pro-Cog 58.17 (8.53) and on the Pro-Emo was 41.50 (9.20), respectively. 
Paired Samples T-Tests showed that there is a statistically significant difference in means between the Per-Cog and Per-Emo settings (Sig < 0.001), the Pro-Cog and Pro-Emo (Sig < 0.001), the Per-Cog and ProCog $($ Sig $=0.004)$, and the Per-Emo and Pro-Emo (Sig < 0.001).

Females had significantly higher empathy scores on the Per-Cognitive, Per-Emo and Pro-Emo subscales (Table 3). It is noticeable that this cross-sectional study in one medical school in Greece showed that females did not demonstrate statistically significant decline in empathy total score over the course of medical school, with males demonstrating a statistically significant decline in empathy as they began their clinical training (in the fourth year of studies). Interestingly, the empathy measures of senior year female students were higher than the scores of female freshmen (see Fig. 1). A longitudinal cohort study is needed to better measure variations in students' empathy scores throughout medical school.

Table 3

Means and standard deviations (SD) of the Greek version of TCES by gender, and Sig. from Independent Sample T-test for equality of means. Statistically significant differences are noted by *.

\begin{tabular}{|llll|}
\hline subscale & Males mean (SD) & Females mean (SD) & Sig \\
\hline Per-Cog & 54.73 & 58.4 & $0.001^{*}$ \\
\hline Per-Emo & 42.79 & 47.31 & $0.000^{*}$ \\
\hline Pro-Cog & 57.48 & 58.71 & 0.353 \\
\hline Pro-Emo & 36.97 & 43.80 & $0.000^{\star}$ \\
\hline
\end{tabular}

Furthermore, as regards the effect of gender and years of studies on total score, a Two-way ANOVA was conducted that examined the effect of gender and years of studies on total score. An interaction between gender and years of studies could not be demonstrated (Sig. $=0.990)$. Only gender seems to have a main effect on total score. Adjusted $r$ squared suggests that $5.7 \% \%$ of the variance in total score is attributable to gender and years of studies (Table 4 [Additional File])

The Tests of Between-Subjects Effects Table (Table 5 [Additional File]) indicates whether either of the two independent factors or their interaction are statistically significant. Results suggest that only the factor GENDER is statistically significant (Sig. $=0.000)$, while the factor years of studies (Sig. $=0.990)$ and the interaction variable of the two factors are not (see Fig, 1).

Additional statistically significant mean differences found based on Independent T-Test or One-Way ANOVAs (for more than 2 subgroups) for different subgroups of demographic characteristics are described in Table 6 [Additional File]. Important factors that differentiate results are having an ill person in the family, loving animals, year of studies, career intention, religion and interest on ethical issues in medicine.

TCES 
The overall reliability analysis of the TCES questionnaire is high (Cronbach's $\alpha=0.895$, Sig. from Hotelling's T-Squared Test $<0.000)$. The total score is extracted from 172 cases $(76.8 \%$ of total sample). Possible total scores from the 52 items of the TCES range from 52 to 312 . The mean total score of empathy was $203.16(S D=24.089)$ which shows that students have a moderately high empathy. An increased total mean score was estimated for females. One-Way ANOVA tests showed that the loving animals, believing in a God and the interest in medical ethics play an important role in the total mean score of the corresponding subgroups (see Table 7. [Additional File]).

As regards the statistical difference in mean total score of two specialty categories, A (people-oriented specialties) and $\mathrm{T}$ (technology-oriented specialties), there was no significant difference in the mean total score of students that aim to choose technology-oriented specialty (mean total score 205.6) and peopleoriented specialty (mean total score 205.96). There was also no significant difference in the mean score of the subscales for the demographic characteristic of specialty category (Table 8 [Additional File]).

Note, however, that subgroups of 17 demographics did not have statistically significant total mean score differences (see Table 9 [Additional File]).

\section{Discussion}

The preliminary validation of the Greek version of the Toronto Composite Empathy Scale (TCES) demonstrated good validity and reliability (Cronbach's $a=0.895$, Sig. from Hotelling's T-Squared Test < 0.000 ) among medical students and could be further used in case of samples of medical students. The students that participated in our study had a moderately high empathy. As presented below, this is not surprising when measuring empathy among medical students, especially in a Western-oriented country, and given that altruism may be an important motivation for medical students to study medicine.

Furthermore, we examined differences in empathy scores by gender, class year, and carrier intention, love for animals, interest in medical ethics, belief in God, having an ill person in the family. For the most part, the finding of this study support the findings of previous literature. We found clear gender differences in empathy among the participants in the study. Moreover, the students that participated in our study demonstrated empathy decline over the years as medical studies progress. Note, however, that we found a positive correlation between empathy and factors that has not been widely explored or discussed in previous literature relative to the topic of interest, such as love for animals, interest in medical ethics, belief in God, having an ill person in the family. To help readers grain some deeper insight into subjects related to our findings, we attempted to present below a comprehensive summary of previous research on these topics.

\section{Decline of students' empathy during medical studies}

\section{The decline of empathy during medical studies}


Research has shown a striking decline in empathy over the years as medical studies progress $[9,49,56$, 75-84]. More specifically, several studies have shown a steep decrease in empathy among students during their third (clinical) year of medical school, namely, as they begin their clinical training and hence empathic communication is critical $[85,29,77,86]$. Mirani, Shaikh, Tahir found that empathy levels were "highest in first-year students and lowest in final-year students" [87]. Importantly, it is suggested that general empathy declines less than clinical empathy [88]. In this study, in consistency with previous literature, we found a statistically significant important empathy decline among medical students over the course of medical school.

\section{The pattern of decline in empathy}

The pattern of decline in empathy as medical studies progress may be different for males and females or for the various components (dimensions) of empathy as well. To cite just one example, Quince et al. demonstrated no change in the cognitive aspect of empathy during the studies (neither for men nor for women). Furthermore, women's affective empathy demonstrated no change, while men's affective empathy declined slightly during the studies [89]. The decline in empathy during medical studies may be viewed as emotional neutralisation, namely, cynicism [51]. Hojat et al. stated that during the medical studies there may be "escalation of cynicism and atrophy of idealism" [77]. Moreover, note that there may be conflicting patterns in empathy change demonstrated by studies conducted within the same region or between wider geo-sociocultural regions (i.e., between the West and the Far East in the U.S.). A probable explanation for this phenomenon may be an interplay between the general and specific aspects of empathy [36]. At any rate it should be stated that while the decreasing trend of student's empathy over the course of medical school is a multi-factorial and complex process [32], it "is not as indiscriminate (patternless) as once thought" [36].

\section{Challenging the empathy decline}

Studies failed to support the hypothesis of a strong and generalisable trend of decline in empathy over the course of medical school $[23,36,53,81,90-94]$ or found only declines in some aspects of empathy [95]. Surprisingly, authors reported an increase in (clinical) empathy during medical studies [96]. Handford et al. found an increase in the behavioural component of empathy [95]. Interestingly, Chatterjee et al. found that empathy "fell from the first to the third semester, then more or less plateaued, and then rose again in the seventh semester" [43]. Interestingly, it has been argued that this decline may be due to differences in methodology used in research. Note that relative studies are based largely on studies using self-administered tools [23]. The decline in empathy may reflect self-representation changes [84]. Importantly, Ferreira-Valente et al. who contested the reliability of the decline of empathy as medical students begin their clinical training, conducted a review and concluded that the decline in empathy may be due to differences across the conducted studies in design, tools used and sample sizes [97]. The authors identified differences between cross-sectional and longitudinal studies [97]. The fact that physicians often are fully aware of the behavioural changes in themselves and their colleagues [49], may affect study results. 


\section{Factors affecting empathy decline}

Culture and the educational background of students at admission may affect the trajectory of empathy levels across the years of medical education. While the decline of empathy levels as medical students progress has been noticed in many studies conducted in the United States, Europe or China, this was not the case with studies conducted in other contexts (i.e. Japan, Iran, Ethiopia, Portugal). This may be due to different cultural contexts or students' educational backgrounds at admission [17, 36]. Note, however, that in a study, Pakistani medical students showed lower levels of empathy as compared to medical students in Western countries [98]. Empathy is a locally construed global construct [36].

Several and complex factors may drive or tackle the decrease of empathy trajectory during medical studies. Understanding the drivers of empathy decline is an important but difficult task. Not surprisingly, "determining with certainty whether it is more likely to change or to remain stable throughout medical studies has proven to be inconclusive" [99]. The lower the students' empathic ability at the beginning of their studies the stronger the decline of their empathy levels during their studies [56, 99]. Students with high empathy levels may show not decreasing but stable trajectory during their studies [99]. Moreover, the students' personality in the entry year may play a crucial role in forming the empathy trajectory during their studies [99].

Studies have shown relationship between medical students' personality and empathy [100-103]. Furthermore, it is suggested that medical students' attachment styles predict empathy dimensions" [104].

Medical students' altruistic motives for studying medicine when entering medical school are associated with greater empathy $[105,106]$. The promotion of altruistic and interpersonally oriented motives may tackle the decrease of empathy trajectory during medical studies [99]. Empathy is considered a "motivated phenomenon" "in which people may choose to experience or avoid the process of understanding other people's emotions" [107]. Findyartini et al. explored the relationship between empathy and students' motivation types [25]. Kusurkar et al. provided four motivational profiles. They state that "there are different theories of motivation; some focus on quantity of motivation and others on quality" [108]. The authors provide four types of extrinsic motivation: integrated regulation, identified regulation, introjected regulation, external regulation [108]. Duan argues that motivation affects the aspects of empathy in different ways [109]. The author suggests that sadness of the target person causes increased cognitive empathy whereas the happiness of the target person causes increased affective empathy [109]. Further research is required to further explore the cited in the literature factors and identify factors that contribute to changes in empathy [110].

Workplace stress and fatigue secondary to workload and increasing levels of clinical responsibility are cited in literature as factors promoting empathy decline among physicians [49]. Furthermore, "sleep loss has been shown to affect some aspects of empathy" [111]. It has been argued that the decline of medical students' empathy during their studies may be a self-protective or coping mechanism at times of transition [23, 112-114]. However, Triffaux, Tisseron, Nasello ask whether the decline of empathy among medical students is useful coping process or dehumanization [84]. Furthermore, the fact that medical 
curriculum focuses more mechanistic view on illness (that may reduce the patients to a disease or an object) than humanistic values may tackle empathy decline during medical studies [5]. It is arguably said that "the more doctors depend solely on technology, the more they lose their humanism" [110]. This assumption has been supported by a systematic review and meta-synthesis of qualitative studies [115].

\section{Empathy and carrier interest / specialty interest}

It is widely argued that empathy drives students to select specific specialties. Students preferring technology-oriented specialties (i.e., radiology, pathology, surgery) have lower empathy levels while students preferring people-oriented specialties (i.e., family medicine, pediatrics, internal medicine, psychiatry) have higher empathy levels $[5,9,49,56,80,84,85,91,93,101,116]$. Note, however, that some studies did not support the hypothesis of relationship between empathy specialty preference $[117,118]$. As presented in Results section above, we found no statistically significant correlation between empathy and specialty interest among participants in this study. Moreover, we explored the students' carrier intention, namely, whether they were interested in practicing medicine in the public or in the private sector, or even following academic carrier. However, we found no statistically significant correlation between empathy and carrier interest among participants in this study.

\section{Empathy gender differences}

The empathy gender bias is a strong effect observed in several empathy-related phenomena [84]. Longitudinal and cross-sectional research has consistently associated the empathy of medical students with gender $[9,43,75,80,97,119,120]$. Many studies have reported gender differences with females scoring higher or significantly higher than men $[2,9,56,75,77,79,85,87,89,93,96,101,103,121-123]$. In many studies male students showed a more significant empathy decline than females during the studies. For instance, Raof and Yassin found that female students had significantly higher empathy levels than male students who showed a significant empathy decline during the studies [116]. Shashikumar et al. did not found significant difference among female students in different semesters. However, they found significant decline in empathy among male students [82]. Ye et al. found no significant gender differences in the empathy scores among medical students before early clinical contact. Note, however, that authors reported no empathy gender differences [59]. Di Lillo et al. found that although females had slightly higher empathy levels the difference was not statistically significant [124]. In the same vein were Iranian studies [92, 125]. The study of Tariq, Rasheed, Tavakol with Pakistani students did not support the hypothesis that female medical students have higher empathy levels than males [98]. Cultural context may be a factor affecting the gender differences in the empathy scores among medical students. As presented in Results section above, we found statistically significant empathy gender differences among participants in our study.

Importantly, it is arguable that further research is necessary to explore the relationship between gender and clinical empathy levels [43]. Christov-Moore et al. state that further investigation of sex/gender differences in empathetic skill may be informative for understanding the nature of empathy [1]. Moreover, 
it is argued that "gender differences in response to medical humanities programs require further study" [6].

Difference by gender may be more evident for some components of empathy. Quince et al. found statistically significant gender differences which however were not same in affective and cognitive empathy. As regards affective empathy, gender differences were found in all six years while cognitive empathy gender differences were found for four of the six years [89]. Many studies argued that the difference by gender is "more evident for the caring component than the sharing component" [44]. To cite just one example, Ishikawa et al. found that "female students manage to maintain their patient-centered attitude while presumably going through comparable experiences in their medical training" [44].

Among the reasons cited in the literature for the empathy gender differences are included: traditional gender roles [43], intra- and inter- cultural gender-related personality characteristics [53], the fact that selfreporting tools used in research methodology may induce biases in favor of gender-based stereotypes [126], or even "phylogenetic and ontogenetic roots" [1]. Shashikumar et al. stated that female students are by nature more caring and loving [82]. Christov-Moore et al. state that "there is also a small but growing literature on gender differences in the ability to recognize emotional body language" and that "females are faster and more accurate than males in recognizing facial expressions" [1]. Note that the understanding of the mechanisms underlying different subtypes of empathy is increasing [127]. Some studies highlighted the gender-related differences between the neurobiological underpinnings of empathy [1]. Schulte-Rüther et al. suggested that "females recruit areas containing mirror neurons to a higher degree than males during both SELF- and OTHER-related processing in empathic face-to-face interactions. This may underlie facilitated emotional "contagion" in females" [128]. Note, however, that in the neuroscience of empathy there may be methodological and conceptual pitfalls [129]. It is not clear whether or not there is significant difference in the activation of the various brain structures between men and women.

Ultimately, empathy gender differences may be due to the method used in the research. Some authors suggest that, when a self-report method is used to assess empathy, women's gender-role model is activated and hence they respond more empathically [130]. It is suggested that differences in general emotional responsiveness may be the reason for gender differences in self-reported empathy [131].

\section{Religiosity / Spirituality}

Empathy and religiosity seem to be linked as both underline values such as altruism, sympathy, helping and caring for others. Málaga, Gayoso and Vásquez found higher levels of empathy according to religious beliefs among medical students ("practicing a religious denomination is related to a higher level of empathy") [123].

However, there is not a clear positive correlation between religiosity and empathy in the literature. Damiano, DiLalla et al. found that "spirituality openness was related to empathy only in nondepressed students. Empathy of students with higher levels of depression was generally lower and not affected by spirituality openness" [132]. Empathy may have a mediating role between emotional intelligence and 
religiosity [133]. Damiano et al. found "that meaning of life and previous mental health treatment but not Religiosity were positively related to empathy" [134]. At any rate, the relationship between religiosity and empathy needs further research. Note that in this study we found a (statistically significant) positive correlation between trust in God and empathy among participants in our study.

\section{The factor age}

In this study, we found no statistically significant correlation between participants' age and empathy among participants in our study. Studies have shown a negative association between age and (cognitive) empathy. For instance, it is argued that a large subset of elderly people experience a decline in their social understanding abilities with advancing years [135] ["Happé, Winner, and Brownell reported that theory of mind performance was superior in the elderly [136]. Yet, in direct contrast to these findings, Maylor, Moulson, Muncer, and Taylor report a decline in theory of mind abilities with advancing years" [137]]. Studies have found reduced neural responses in brain activity associated to empathy in older adults [138, 139]. Chen et al. found that "the neural response associated with emotional empathy lessened with age, whereas the response to perceived agency is preserved" [138]. Many studies have suggested that while cognitive empathy declines with advancing age, there is no age-related difference in affective empathy [140].

\section{Limitations}

Some limitations on the use of a self-reported questionnaire to measure empathy can be raised. Braun et al. stated: "For more than 30 years, the Interpersonal Reactivity Index (IRI) has been used to measure the multidimensional aspects of empathy" [141]. First, data identified by self-reported empathy instruments may involve lack of accuracy and biases causing respondents to adopt traditional gender-based stereotypes $[73,126]$. Second, as empathy is a psychosocial phenomenon, qualitative studies play a considerable role in providing further insight into empathy and capture the complexities of human experience concerning empathy [73]. Third, it is arguably stated that perspective-taking subscales may support the understanding of another's emotions rather than the understanding of another's perspective [31]. It is argued that "a discrepancy exists between self-administered empathy scores and observed empathic behaviours" [23]. As medical students acculturate to illness and suffering through real-world experience, their behavioural skills may evolve, thus developing a trend towards better patient-centred communication [42]. Therefore, the decline of empathy on a self-administered tool, may "not sufficiently predict actual empathic behaviour towards patients" [23].

Furthermore, this study is a cross-sectional study. In literature, both cross-sectional and longitudinal studies have been conducted to explore the phenomenon empathy among medical students. Moreover, this study has used group-level method. This is another limitation of this study. It is true that the vast majority of longitudinal studies on medical student empathy have used group-level methods which, however, cannot assess inter-individual changes (namely, differences between individuals) and intraindividual changes (namely, differences within the same person over time) [97, 99]. "An understanding of empathy would be incomplete without a consideration of individual differences" [1]. 
Finally, and most importantly, in this study, an increased number of missing values was obtained for Professional setting. A significant negative correlation was found between the number of missing replies of each participant and the study year (Pearson $=-0.336$, Sig. $<0.000$ ), with students from 1 rst and 2 nd years mainly not responding to most items.

\section{Conclusion}

The preliminary validation of the Greek version of the Toronto Composite Empathy Scale (TCES) demonstrated acceptable validity and reliability among medical students and could be further tested in larger samples of medical students. The overall reliability analysis of the TCES questionnaire is high (Cronbach's $a=0.895$, Sig. from Hotelling's T-Squared Test $<0.000$ ). The mean total score of empathy showed that students have a moderately high empathy. The 52-item TCES, 26 for the personal (Per) setting and another 26 for professional (Pro) life, equally divided into cognitive (Cog) and emotional (Emo) empathy in each case. It was found that there is a statistically significant difference in means between the Per-Cog and Per-Emo settings (Sig < 0.001), the Pro-Cog and Pro-Emo (Sig < 0.001), the PerCog and Pro-Cog (Sig = 0.004), and the Per-Emo and Pro-Emo (Sig<0.001). Females had significantly higher empathy scores (mean score 208.04) than males (mean score 192.5) on the Per-Cognitive, Per-Emo and Pro-Emo subscales. Furthermore, a positive correlation was found between empathy and factors such as love for animals, interest in medical ethics, belief in God, having an ill person in the family, class year or carrier intention. For the most part our findings were consistent with previous literature.

\section{Abbreviations}

TCES $=$ Toronto Composite Empathy Scale

$\mathrm{GMC}=$ General Medical Council

AAMC $=$ Association of American Medical Colleges

PAM $=$ Perception-action model

IRI = Interpersonal Reactivity Index

SPSS $=$ Statistical Product and Service Solutions

IBM - International Business Machines Corporation

SD = Standard Deviation

ANOVA = Analysis of variance

\section{Declarations}

\section{Availability of data and materials}


The authors declare that the data analyzed during the current study and supporting the findings of this study are available from the corresponding author on reasonable request.

\section{Acknowledgements}

The authors are grateful to the participants of this study for their collaboration.

\section{Funding}

There are no sources of funding to be declared.

\section{Author information}

\section{Affiliations}

1. Laboratory of Forensic Medicine \& Toxicology (Medical Law and Ethics), School of Medicine, Faculty of Health Sciences, Aristotle University, University Campus, GR-541 24, Thessaloniki, Greece. Voultsos Polychronis (Associate Professor of Medical Law and Ethics, Corresponding Author), Chatzinikolaou Fotios (Associate Professor of Forensic Medicine).

2. Department of Economics, School of Economics and Regional Studies, University of Macedonia, Egnatia Str 156, GR-546 36 Thessaloniki, Greece. Angeliki Papana (Postdoctoral Researcher).

3. AHEPA University Hospital, Kiriakidi Str 1, GR-546 21Thessaloniki, Greece. Aspasia Deliliga (Forensic Pathologist M.D., MSc, PhD).

\section{Contributions}

PV developed the study concept and design. AP developed and performed the statistical analyses. PV analysed and interpreted the data. The authors PV, FC and AD was involved in the data analysis discussions and monitored the process of this study. PV and AP drafted the manuscript, and all authors provided critical revisions for important intellectual content. The study was supervised by PV and FC. All authors read and approved the final manuscript.

\section{Corresponding author}

Correspondence to Polychronis Voultsos.

\section{Ethics declarations}

\section{Ethics approval and consent to participate}

Written informed consent was obtained from participants. Before starting to fill out the questionnaire, each participant was given information on the study, placing great weight on the importance of maintaining confidentiality. This study and consent procedure was approved and monitored by the 
Research Ethics Review Board of the School of Medicine, Faculty of Health Sciences, Aristotle University of Thessaloniki, Greece (Decision Number: 5/23.2.2021). In addition, we confirm that all methods were performed in accordance with the relevant guidelines and regulations.

\section{Consent for publication}

Not applicable

\section{Competing interests}

The authors declare that they have no competing interests.

\section{References}

1. Christov-Moore L, Simpson EA, Coudé G, Grigaityte K, lacoboni M, Ferrari PF. Empathy: gender effects in brain and behavior. Neurosci Biobehav Rev. 2014;46 Pt 4(Pt 4):604-627.

2. Hojat M, Gonnella JS, Nasca TJ, Mangione S, Vergare M, Magee M. Physician empathy: definition, components, measurement, and relationship to gender and specialty. Am J Psychiatry. 2002 Sep;159(9): 1563-9.

3. Mercer SW, Reynolds WJ. Empathy and quality of care. Br J Gen Pract. 2002 Oct;52 Suppl(Suppl):S912.

4. Givron H, Desseilles M. Decline of Empathy after the First Internship: Towards a More Functional Empathy? Sante Ment Que. 2020 Spring;45(1):183-200. PMID: 33270405.

5. Andersen FA, Johansen AB, Søndergaard J, Andersen CM, Assing Hvidt E. Revisiting the trajectory of medical students' empathy, and impact of gender, specialty preferences and nationality: a systematic review. BMC Med Educ. 2020 Feb 17;20(1):52.

6. Lwow M, Canetti L, Muszkat M. Gender differences in the effect of medical humanities program on medical students' empathy: a prospective longitudinal study. BMC Med Educ. 2020 Nov 10;20(1):413.

7. Halpern J. What is clinical empathy? J Gen Intern Med. 2003 Aug;18(8):670-4.

8. Larson EB, Yao X. Clinical empathy as emotional labor in the patient-physician relationship. JAMA. 2005 Mar 2;293(9):1100-6. doi: 10.1001/jama.293.9.1100. PMID: 15741532.

9. Hojat M, Gonnella JS, Nasca TJ, Mangione S, Veloksi JJ, Magee M. The Jefferson Scale of Physician Empathy: further psychometric data and differences by gender and specialty at item level. Acad Med. 2002 Oct;77(10 Suppl): S58-60.

10. Moul C, Hawes DJ, Dadds MR. Mapping the developmental pathways of child conduct problems through the neurobiology of empathy. Neurosci Biobehav Rev. 2018 Aug;91:34-50. doi:

10.1016/j.neubiorev.2017.03.016. Epub 2017 Apr 1. PMID: 28377098.

11. Decety J. The neurodevelopment of empathy in humans. Dev Neurosci. 2010;32(4):257-67.

12. Decety J, Jackson PL. The functional architecture of human empathy. Behav Cogn Neurosci Rev. 2004 Jun;3(2):71-100. 
13. Bayot, M. (2017). Pleine conscience et empathie: impact des composants cognitifs, émotionnels et éthiques de la pleine conscience dans sa relation au phénomène empathique, UCL, Louvain-la-Neuve. Retrieved from:

file:///C:/Users/voult/AppData/Local/Temp/Manuscrit\%20de\%CC\%81fense\%20publique_MBayot.pdf (last access: 31 March 2021).

14. Huang L, Thai J, Zhong Y, Peng H, Koran J, Zhao XD. The Positive Association Between Empathy and Self-Esteem in Chinese Medical Students: A Multi-Institutional Study. Front Psychol. 2019 Aug 21;10:1921.

15. Morse JM, Anderson G, Bottorff JL, Yonge O, O'Brien B, Solberg SM, Mcllveen KH. Exploring empathy: a conceptual fit for nursing practice? Image J Nurs Sch. 1992 Winter;24(4):273-80.

16. Stepien KA, Baernstein A. Educating for empathy. A review. J Gen Intern Med. 2006 May;21(5):524-30. doi: 10.1111/j.1525-1497.2006.00443.x. PMID: 16704404; PMCID: PMC1484804.

17. Sng G, Tung J, Ping YS, Lee SS, Win MT, Hooi SC, Samarasekera DD. Complex and novel determinants of empathy change in medical students. Korean J Med Educ. 2016 Mar;28(1):67-78.

18. Rizzolatti G, Caruana Some considerations on de Waal and Preston review. Nat Rev Neurosci. 2017 Dec;18(12):769.

19. de Waal FBM, Preston SD. Mammalian empathy: behavioural manifestations and neural basis. Nat Rev Neurosci. 2017 Aug;18(8):498-509.

20. Preston SD, de Waal Only the PAM explains the personalized nature of empathy. Nat Rev Neurosci. 2017 Dec;18(12):769.

21. Batson CD. These things called empathy: Eight related but distinct phenomena. In J. Decety \& W. Ickes (Eds.), Social neuroscience. The social neuroscience of empathy 2009, p. 3-15.

22. Sulzer SH, Feinstein NW, Wendland CL. Assessing empathy development in medical education: a systematic review. Med Educ. 2016 Mar;50(3):300-10.

23. Teng VC, Nguyen C, Hall KT, Rydel T, Sattler A, Schillinger E, Weinlander E, Lin S. Rethinking empathy decline: results from an OSCE. Clin Teach. 2017 Dec;14(6):441-445.

24. Hojat M, LaNoue M. Exploration and confirmation of the latent variable structure of the Jefferson scale of empathy. Int J Med Educ. 2014 Apr 20; 5:73-81.

25. Findyartini A, Felaza E, Setyorini D, Mustika R. Relationship between empathy and motivation in undergraduate medical students. GMS J Med Educ. 2020 Jun 15;37(4): Doc43.

26. Gladstein GA. Understanding empathy: integrating counseling, developmental and social psychologyperspectives", Journal of Counseling Psychology 1983; , 30 (4): 467-482.

27. Preston SD, de Waal FB. Empathy: Its ultimate and proximate bases. Behav Brain Sci. 2002 Feb;25(1):1-20; discussion 20-71.

28. Preston SD, Stansfield RB. I know how you feel: task-irrelevant facial expressions are spontaneously processed at a semantic level. Cogn Affect Behav Neurosci. 2008 Mar;8(1):54-64. 
29. Stansfield RB, Schwartz A, O'Brien CL, Dekhtyar M, Dunham L, Quirk M. Development of a metacognitive effort construct of empathy during clinical training: a longitudinal study of the factor structure of the Jefferson Scale of Empathy. Adv Health Sci Educ Theory Pract. 2016 Mar;21(1):5-17.

30. Lamm C, Batson CD and Decety J. The neural substrate of human empathy: Effects of perspectivetaking and cognitive appraisal. Journal of Cognitive Neuroscience 2007; 19(1): 42-58.

31. Jolliffe D, Farrington DP. Development and validation of the Basic Empathy Scale. J Adolesc. 2006 Aug;29(4):589-611.

32. Smith KE, Norman GJ, Decety J. The complexity of empathy during medical school training: evidence for positive changes. Med Educ. 2017 Nov;51(11):1146-1159.

33. Hojat M. Empathy in patient care: Antecedents, development, measurement, and outcomes. Springer Science + Business Media. 2007.

34. Decety J, Lamm C. Empathy versus personal distress: Recent evidence from social neuroscience. In J. Decety \& W. Ickes (Eds.), Social neuroscience. The social neuroscience of empathy, 2009, pp. 199213.

35. Preusche I, Lamm C. Reflections on empathy in medical education: What can we learn from social neurosciences? Adv Health Sci Educ Theory Pract. 2016 Mar;21(1):235-49.

36. Ponnamperuma G, Yeo SP, Samarasekera DD. Is empathy change in medical school geosocioculturally influenced? Med Educ. 2019 Jul;53(7):655-665.

37. Matthews DA, Suchman AL, Branch WT Jr. Making "connexions": enhancing the therapeutic potential of patient-clinician relationships. Ann Intern Med. 1993 Jun 15;118(12):973-7.

38. Derksen F, Bensing J, Lagro-Janssen A. Effectiveness of empathy in general practice: a systematic review. Br J Gen Pract. 2013 Jan;63(606): e76-84.

39. Hojat M, Louis DZ, Markham FW, Wender R, Rabinowitz C, Gonnella JS. Physicians' empathy and clinical outcomes for diabetic patients. Acad Med. 2011 Mar;86(3):359-64.

40. Kim SS, Kaplowitz S, Johnston MV. The effects of physician empathy on patient satisfaction and compliance. Eval Health Prof. 2004 Sep;27(3):237-51.

41. Rakel D, Barrett B, Zhang Z, Hoeft T, Chewning B, Marchand L, Scheder J. Perception of empathy in the therapeutic encounter: effects on the common cold. Patient Educ Couns. 2011 Dec;85(3):390-7.

42. Chen DC, Pahilan ME, Orlander JD. Comparing a self-administered measure of empathy with observed behavior among medical students. J Gen Intern Med. 2010 Mar;25(3):200-2.

43. Chatterjee A, Ravikumar R, Singh S, Chauhan PS, Goel M. Clinical empathy in medical students in India measured using the Jefferson Scale of Empathy-Student Version. J Educ Eval Health Prof. 2017 Dec 27; 14:33.

44. Ishikawa H, Son D, Eto M, Kitamura K, Kiuchi T. Changes in patient-centered attitude and confidence in communicating with patients: a longitudinal study of resident physicians. BMC Med Educ. 2018 Jan 25;18(1):20. 
45. Yu J, Lee S, Kim M, Lim K, Chang K, Lee M. Relationships Between Perspective-Taking, Empathic Concern, and Self-rating of Empathy as a Physician Among Medical Students. Acad Psychiatry. 2020 Jun;44(3):316-319.

46. Laughey WF, Brown MEL, Dueñas AN, Archer R, Whitwell MR, Liu A, Finn GM. How medical school alters empathy: Student love and break up letters to empathy for patients. Med Educ. 2020 Oct 30.

47. Hojat M. Ten approaches for enhancing empathy in health and human services cultures. $J$ Health Hum Serv Adm. 2009 Spring;31(4):412-50.

48. Steinhausen S, Ommen O, Antoine SL, Koehler T, Pfaff H, Neugebauer E. Short- and long-term subjective medical treatment outcome of trauma surgery patients: the importance of physician empathy. Patient Prefer Adherence. 2014 Sep 18;8:1239-53.

49. Stratta EC, Riding DM, Baker P. Ethical erosion in newly qualified doctors: perceptions of empathy decline. Int J Med Educ. 2016 Sep 6; 7:286-92.

50. Smith KE, Norman GJ, Decety J. Medical students' empathy positively predicts charitable donation behavior. J Posit Psychol. 2020;15(6):734-742.

51. Peng J, Clarkin C, Doja A. Uncovering cynicism in medical training: a qualitative analysis of medical online discussion forums. BMJ Open. 2018 Oct 18;8(10):e022883.

52. D'souza PC, Rasquinha SL, D'souza TL, Jain A, Kulkarni V, Pai K. Effect of a Single-Session Communication Skills Training on Empathy in Medical Students. Acad Psychiatry. 2020 Jun;44(3):289-294.

53. Costa P, Magalhães E, Costa MJ. A latent growth model suggests that empathy of medical students does not decline over time. Adv Health Sci Educ Theory Pract. 2013 Aug;18(3):509-22.

54. Huetter FK, Bachmann HS, Reinders A, Siffert D, Stelmach P, Knop D, Horn PA, Siffert W. Association of a Common Oxytocin Receptor Gene Polymorphism with Self-Reported 'Empathic Concern' in a Large Population of Healthy Volunteers. PLoS One. 2016 Jul 28;11(7):e0160059.

55. Kataoka H, Iwase T, Ogawa H, Mahmood S, Sato M, DeSantis J, Hojat M, Gonnella JS. Can communication skills training improve empathy? A six-year longitudinal study of medical students in Japan. Med Teach. 2019 Feb;41(2):195-200.

56. Chen DC, Kirshenbaum DS, Yan J, Kirshenbaum E, Aseltine RH. Characterizing changes in student empathy throughout medical school. Med Teach. 2012;34(4):305-11.

57. Sherman JJ, Cramer A. Measurement of changes in empathy during dental school. J Dent Educ. 2005 Mar;69(3):338-45.

58. Dehning S, Gasperi S, Krause D, Meyer S, Reiß E, Burger M, Jacobs F, Buchheim A, Müller N, Siebeck M. Emotional and cognitive empathy in first-year medical students. ISRN Psychiatry. 2013 Oct 21;2013:801530.

59. Ye X, Guo H, Xu Z, Xiao H. Empathy variation of undergraduate medical students after early clinical contact: a cross-sectional study in China. BMJ Open. 2020 Jul 19;10(7):e035690.

60. Kelm Z, Womer J, Walter JK, Feudtner C. Interventions to cultivate physician empathy: a systematic review. BMC Med Educ. 2014 Oct 14;14:219. doi: 10.1186/1472-6920-14-219. 
61. Van Winkle LJ, Fjortoft N, Hojat Impact of a workshop about aging on the empathy scores of pharmacy and medical students. Am J Pharm Educ. 2012;76:9.

62. General Medical Council. 2009. Tomorrow's doctors. London: GMC. Krupat E, Pelletier S, Alexander EK, Hirsh D.

63. General Medical Council. Your Health Matters. GMC, 2010. http://www.gmcuk.org/doctors/information_for_doctors/7033.asp (last access: 31 March 2021).

64. Association of American Medical Schools (AAMC). Learning objectives for medical student education -guidelines for medical schools: Report I of the Medical School Objectives Project. Acad Med 1999a; 74:13-8.

65. Association of American Medical Colleges (AAMC). Report III: Contemporary issues in medicine. Communication in medicine: Spirituality, cultural issues and end of life care. Medical School Objectives Project. Washington, DC, Association of American Medical Colleges. 1999b.

66. Olsen LD, Gebremariam Disciplining empathy: Differences in empathy with U.S. medical students by college major. Health (London). 2020 Oct 19:1363459320967055.

67. Santiago LM, Rosendo I, Coutinho ML, Maurício KS, Neto I, Simões JA. Comparing empathy in medical students of two Portuguese medicine schools. BMC Med Educ. 2020 May 13;20(1):153.

68. Hojat M, Shannon SC, DeSantis J, Speicher MR, Bragan L, Calabrese LH. Does Empathy Decline in the Clinical Phase of Medical Education? A Nationwide, Multi-Institutional, Cross-Sectional Study of Students at DO-Granting Medical Schools. Acad Med. 2020 Jun;95(6):911-918.

69. Rivas JO. Developing empathy in medical students. Clin Teach. 2019 Dec;16(6):657.

70. Davison E, Lindqvist Medical students working as health care assistants: an evaluation. Clin Teach. 2020 Aug;17(4):382-388.

71. Hirsch EM. The Role of Empathy in Medicine: A Medical Student's Perspective. Virtual Mentor. 2007 Jun $1 ; 9(6): 423-7$.

72. Rasasingam D, Kerry G, Gokani S, Zargaran A, Ash J, Mittal A. Being a patient: a medical student's perspective. Adv Med Educ Pract. 2017 Feb 15; 8:163-165.

73. Tavakol S, Dennick R, Tavakol M. Medical students' understanding of empathy: a phenomenological study. Med Educ. 2012 Mar;46(3):306-16.

74. Tsiantou D, Lazaridou D, Coolidge T, Arapostathis KN, Kotsanos N. Psychometric properties of the Greek version of the Toronto Composite Empathy Scale in Greek dental students. Eur J Dent Educ. 2013 Nov;17(4):208-17.

75. Hojat M, Gonnella JS, Mangione S, Nasca TJ, Veloski JJ, Erdmann JB, Callahan CA, Magee M. Empathy in medical students as related to academic performance, clinical competence and gender. Med Educ. 2002 Jun;36(6): 522-7.

76. Hojat M, Mangione S, Nasca TJ, Rattner S, Erdmann JB, Gonnella JS, Magee M. An empirical study of decline in empathy in medical school. Med Educ. 2004 Sep;38(9):934-41. 
77. Hojat M, Vergare MJ, Maxwell K, Brainard G, Herrine SK, Isenberg GA, Veloski J, Gonnella JS. The devil is in the third year: a longitudinal study of erosion of empathy in medical school. Acad Med. 2009 Sep;84(9):1182-91.

78. Michalec B. An Assessment of Medical School Stressors on Preclinical Students' Levels of Clinical Empath, Current Psychology 2010; 29: 210-221.

79. Shariat SV, Habibi M. Empathy in Iranian medical students: measurement model of the Jefferson scale of empathy. Med Teach. 2013;35(1):e913-8.

80. Neumann M, Edelhäuser F, Tauschel D, Fischer MR, Wirtz M, Woopen C, Haramati A, Scheffer C. Empathy decline and its reasons: a systematic review of studies with medical students and residents. Acad Med. 2011 Aug;86(8):996-1009.

81. Spencer J. Decline in empathy in medical education: how can we stop the rot? Med Educ. 2004 Sep;38(9):916-8.

82. Shashikumar R, Chaudhary R, Ryali VS, Bhat PS, Srivastava K, Prakash J, Basannar D. Cross sectional assessment of empathy among undergraduates from a medical college. Med $\mathrm{J}$ Armed Forces India. 2014 Apr;70(2):179-85.

83. Mostafa A, Hoque R, Mostafa M, Rana MM, Mostafa F. Empathy in undergraduate medical students of bangladesh: psychometric analysis and differences by gender, academic year, and specialty preferences. ISRN Psychiatry. 2014 Apr 7;2014:375439.

84. Triffaux JM, Tisseron S, Nasello JA. Decline of empathy among medical students: Dehumanization or useful coping process? Encephale. 2019 Feb;45(1):3-8.

85. Chen D, Lew R, Hershman W, Orlander J. A cross-sectional measurement of medical student empathy. J Gen Intern Med. 2007 Oct;22(10):1434-8.

86. Shapiro J, Youm J, Kheriaty A, Pham T, Chen Y, Clayma R. The human kindness curriculum: An innovative preclinical initiative to highlight kindness and empathy in medicine. Educ Health (Abingdon). 2019 May-Aug;32(2):53-61.

87. Mirani SH, Shaikh NA, Tahir A. Assessment of Clinical Empathy Among Medical Students Using the Jefferson Scale of Empathy-Student Version. Cureus. 2019 Feb 28;11(2):e4160.

88. Akgün Ö, Akdeniz M, Kavukcu E, Avcı HH. Medical Students' Empathy Level Differences by Medical Year, Gender, and Specialty Interest in Akdeniz University. J Med Educ Curric Dev. 2020 Jul $31 ; 7: 2382120520940658$.

89. Quince TA, Parker RA, Wood DF, Benson JA. Stability of empathy among undergraduate medical students: a longitudinal study at one UK medical school. BMC Med Educ. 2011 Oct 25;11: 90.

90. Coulehan J, Williams PC. Vanquishing virtue: the impact of medical education. Acad Med. 2001 Jun;76(6):598-605.

91. Newton BW, Barber L, Clardy J, Cleveland E, O'Sullivan P. Is there hardening of the heart during medical school? Acad Med. 2008 Mar;83(3):244-9.

92. Rahimi-Madiseh M, Tavakol M, Dennick R, Nasiri J. Empathy in Iranian medical students: A preliminary psychometric analysis and differences by gender and year of medical school. Med Teach. 
2010;32(11):e471-8.

93. Tavakol S, Dennick R, Tavakol M. Empathy in UK medical students: differences by gender, medical year and specialty interest. Educ Prim Care. 2011 Sep;22(5):297-303.

94. Colliver JA, Conlee MJ, Verhulst SJ, Dorsey JK. Reports of the decline of empathy during medical education are greatly exaggerated: a reexamination of the research. Acad Med. 2010 Apr;85(4):58893.

95. Handford C, Lemon J, Grimm MC, Vollmer-Conna U. Empathy as a function of clinical exposure-reading emotion in the eyes. PLoS One. 2013 Jun 5;8(6):e65159.

96. Kataoka HU, Koide N, Ochi K, Hojat M, Gonnella JS. Measurement of empathy among Japanese medical students: psychometrics and score differences by gender and level of medical education. Acad Med. 2009 Sep;84(9):1192-7.

97. Ferreira-Valente A, Monteiro JS, Barbosa RM, Salgueira A, Costa P, Costa MJ. Clarifying changes in student empathy throughout medical school: a scoping review. Adv Health Sci Educ Theory Pract. 2017 Dec;22(5):1293-1313.

98. Tariq N, Rasheed T, Tavakol M. A Quantitative Study of Empathy in Pakistani Medical Students: A Multicentered Approach. J Prim Care Community Health. 2017 Oct;8(4):294-299.

99. Piumatti G, Abbiati M, Baroffio A, Gerbase MW. Empathy trajectories throughout medical school: relationships with personality and motives for studying medicine. Adv Health Sci Educ Theory Pract. 2020 Dec;25(5):1227-1242.

100. Costa P, Alves R, Neto I, Marvão P, Portela M, Costa MJ. Associations between medical student empathy and personality: a multi-institutional study. PLoS One. 2014 Mar 17;9(3):e89254.

101. Hojat M, Mangione S, Nasca TJ, Gonnella JS, Magee M. Empathy scores in medical school and ratings of empathic behavior in residency training 3 years later. J Soc Psychol. 2005 Dec;145(6):66372

102. Magalhães E, Costa P, Costa MJ. Empathy of medical students and personality: evidence from the Five-Factor Model. Med Teach. 2012;34(10):807-12.

103. Miniotti M. Empathy for patient care in medical students: new evidence on the importance of selftranscendence. Psychol Health Med. 2020 Nov 2:1-7.

104. Ardenghi S, Rampoldi G, Bani M, Strepparava MG. Attachment styles as predictors of self-reported empathy in medical students during pre-clinical years. Patient Educ Couns. 2020 May;103(5):965970.

105. Gonçalves-Pereira M, Trancas B, Loureiro J, Papoila A, Caldas-de-Almeida JM. Empathy as related to motivations for medicine in a sample of first-year medical students. Psychol Rep. 2013 Feb;112(1):73-88.

106. Piumatti G, Abbiati M, Baroffio A, Gerbase MW. Associations between motivational factors for studying medicine, learning approaches and empathy among medical school candidates. Adv Health Sci Educ Theory Pract. 2019 May;24(2):287-300.

107. Zaki J. Empathy: a motivated account. Psychol Bull. 2014 Nov;140(6):1608-47. 
108. Kusurkar RA, Ten Cate TJ, Vos CM, Westers P, Croiset G. How motivation affects academic performance: a structural equation modelling analysis. Adv Health Sci Educ Theory Pract. 2013 Mar;18(1):57-69.

109. Duan, C. Being Empathic: The Role of Motivation to Empathize and the Nature of Target Emotions. Motivation and Emotion 2000; 24: 29-49.

110. Li D, Xu H, Kang M, Ma S. Empathy in Chinese eight-year medical program students: differences by school year, educational stage, and future career preference. BMC Med Educ. 2018 Oct 22;18(1):241.

111. Fowler LA, Ellis S. The Effect of 12 Hour Shifts, Time of Day, and Sleepiness on Emotional Empathy and Burnout in Medical Students. Clocks Sleep. 2019 Dec 6;1(4):501-509.

112. Testerman JK, Morton KR, Loo LK, Worthley JS, Lamberton HH. The natural history of cynicism in physicians. Acad Med. 1996 Oct;71(10 Suppl):S43-5.

113. Bellini LM, Baime M, Shea JA. Variation of mood and empathy during internship. JAMA. 2002 Jun $19 ; 287(23): 3143-6$.

114. Bellini LM, Shea JA. Mood change and empathy decline persist during three years of internal medicine training. Acad Med. 2005 Feb;80(2):164-7.

115. Costa-Drolon E, Verneuil L, Manolios E, Revah-Levy A, Sibeoni J. Medical Students' Perspectives on Empathy: A Systematic Review and Metasynthesis. Acad Med. 2020 Aug 4. doi:

10.1097/ACM.0000000000003655. Epub ahead of print. PMID: 32769475.

116. Raof AM, Yassin BA. Measuring Empathy Levels among Kurdish Medical Students in Erbil City, Iraq: Cross-sectional study. Sultan Qaboos Univ Med J. 2016 Feb;16(1):e62-7.

117. Magalhães E, Salgueira AP, Costa P, Costa MJ. Empathy in senior year and first year medical students: a cross-sectional study. BMC Med Educ. 2011 Jul 29;11:52.

118. Calabrese LH, Bianco JA, Mann D, Massello D, Hojat M. Correlates and changes in empathy and attitudes toward interprofessional collaboration in osteopathic medical students. J Am Osteopath Assoc. 2013 Dec;113(12):898-907.

119. Williams B, Brown T, Boyle M, McKenna L, Palermo C, Etherington J. Levels of empathy in undergraduate emergency health, nursing, and midwifery students: a longitudinal study. Adv Med Educ Pract. 2014 Sep 11;5:299-306.

120. Calzadilla-Núñez A, Díaz-Narváez VP, Dávila-Pontón Y, Aguilera-Muñoz J, Fortich-Mesa N, AparicioMarenco D, Reyes-Reyes A. Erosion of empathy during medical training by gender. A cross-sectional study. Arch Argent Pediatr. 2017 Dec 1;115(6):556-561.

121. Fields SK, Mahan P, Tillman P, Harris J, Maxwell K, Hojat M. Measuring empathy in healthcare profession students using the Jefferson Scale of Physician Empathy: health provider-student version. J Interprof Care. 2011 Jul;25(4):287-93.

122. Rueckert L, Naybar N. Gender differences in empathy: the role of the right hemisphere. Brain Cogn. 2008; 67(2): 162-167.

123. Málaga G, Gayoso D, Vásquez Empathy in medical students of a private university in Lima, Peru: A descriptive study. Medwave. 2020 May 25;20(4):e7905. 
124. Di Lillo M, Cicchetti A, Lo Scalzo A, Taroni F, Hojat M. The Jefferson Scale of Physician Empathy: preliminary psychometrics and group comparisons in Italian physicians. Acad Med. 2009 Sep;84(9):1198-202.

125. Benabbas R. Empathy in Iranian medical students: A comparison by age, gender, academic performance and specialty preferences. Med J Islam Repub Iran. 2016 Nov 7;30: 439.

126. Baez S, Flichtentrei D, Prats M, Mastandueno R, García AM, Cetkovich M, Ibáñez A. Men, women... who cares? A population-based study on sex differences and gender roles in empathy and moral cognition. PLoS One. 2017 Jun 20;12(6):e0179336.

127. Shamay-Tsoory S, Lamm C. The neuroscience of empathy - from past to present and future. Neuropsychologia. 2018 Jul 31;116(Pt A):1-4.

128. Schulte-Rüther M, Markowitsch HJ, Shah NJ, Fink GR, Piefke M. Gender differences in brain networks supporting empathy. Neuroimage. 2008 Aug 1;42(1):393-403.

129. Zaki J, Ochsner KN. The neuroscience of empathy: progress, pitfalls and promise. Nat Neurosci. 2012 Apr 15;15(5):675-80.

130. Michalska KJ, Kinzler KD, Decety J. Age-related sex differences in explicit measures of empathy do not predict brain responses across childhood and adolescence. Dev Cogn Neurosci. 2013 Jan;3: 2232.

131. Rueckert $L$, Branch $B$, Doan Are gender differences in empathy due to differences in emotional reactivity? Psychology 2011; 2: 574-578.

132. Damiano RF, DiLalla LF, Lucchetti G, Dorsey JK. Empathy in Medical Students Is Moderated by Openness to Spirituality. Teach Learn Med. 2017 Apr-Jun;29(2):188-195.

133. Łowicki P, Zajenkowski M, van der Linden The Interplay Between Cognitive Intelligence, Ability Emotional Intelligence, and Religiosity. J Relig Health. 2020 Oct;59(5):2556-2576.

134. Damiano RF, de Andrade Ribeiro LM, Dos Santos AG, da Silva BA, Lucchetti G. Empathy is Associated with Meaning of Life and Mental Health Treatment but not Religiosity Among Brazilian Medical Students. J Relig Health. 2017 Jun;56(3):1003-1017.

135. Sullivan S, Ruffman T. Social understanding: How does it fare with advancing years? Br J Psychol. 2004 Feb;95(Pt 1):1-18.

136. Happé FG, Winner E, Brownell H. The getting of wisdom: theory of mind in old age. Dev Psychol. 1998 Mar;34(2):358-62.

137. Maylor EA, Moulson JM, Muncer AM, Taylor LA. Does performance on theory of mind tasks decline in old age? Br J Psychol. 2002 Nov;93(Pt 4):465-85.

138. Chen YC, Chen CC, Decety J, Cheng Y. Aging is associated with changes in the neural circuits underlying empathy. Neurobiol Aging. 2014 Apr;35(4):827-36.

139. Riva F, Tschernegg M, Chiesa PA, Wagner IC, Kronbichler M, Lamm C, Silani G. Age-related differences in the neural correlates of empathy for pleasant and unpleasant touch in a female sample. Neurobiol Aging. 2018 May;65:7-17. 
140. Bailey PE, Henry JD, Von Hippel Empathy and social functioning in late adulthood. Aging Ment Health. 2008 Jul;12(4):499-503.

141. Braun S, Rosseel Y, Kempenaers C, Loas G, Linkowski P. SELF-REPORT OF EMPATHY: A SHORTENED FRENCH ADAPTATION OF THE INTERPERSONAL REACTIVITY INDEX (IRI) USING TWO LARGE BELGIAN SAMPLES. Psychol Rep. 2015 Dec;117(3):735-53.

\section{Figures}

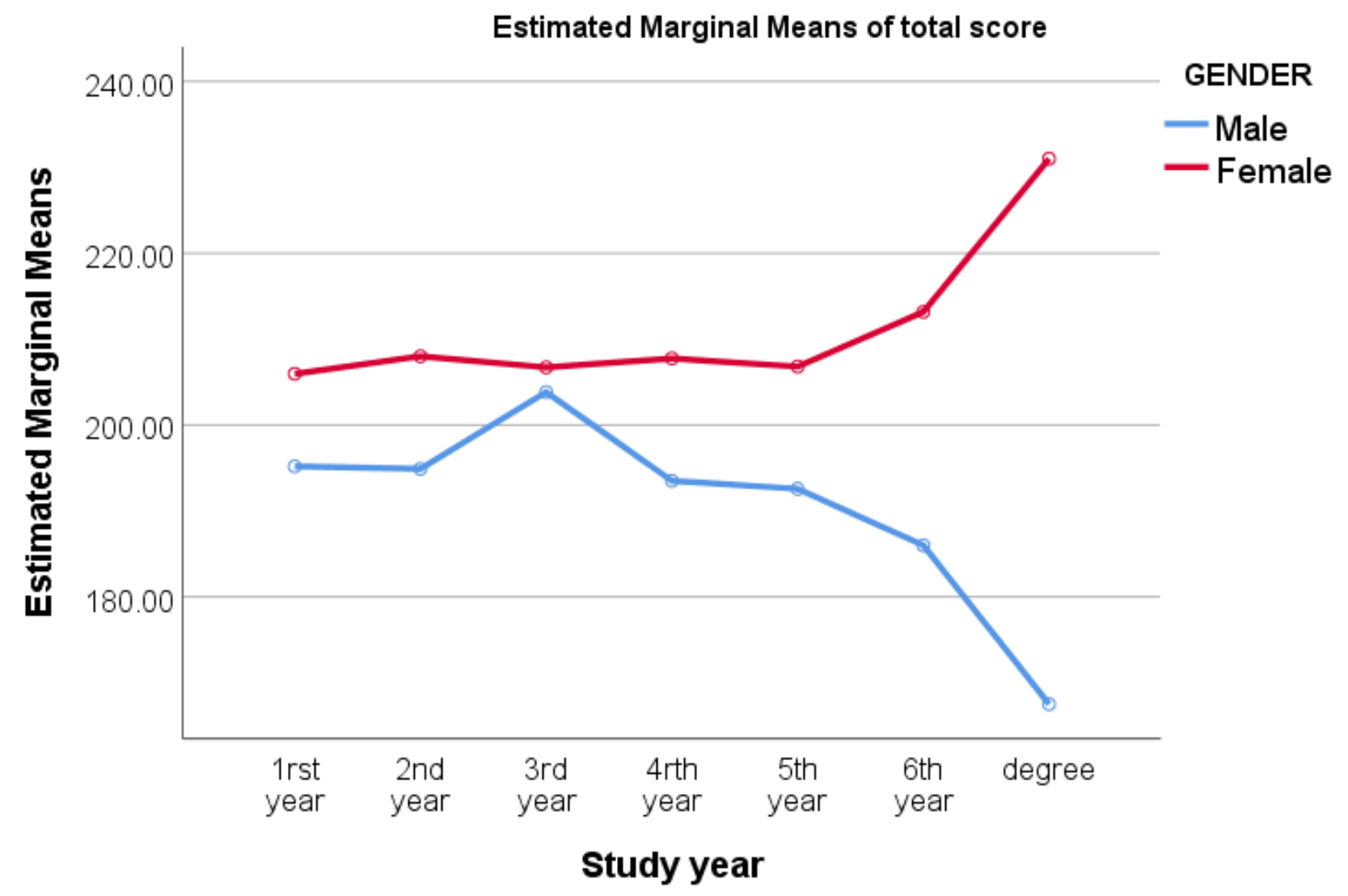

Figure 1

Profile Plot from two-way ANOVA

\section{Supplementary Files}

This is a list of supplementary files associated with this preprint. Click to download.

- EMPATHYTABLES.docx 